\title{
Fabrikasi dan Analisis Kualitas Papan Komposit Semen Berbobot Ringan Berbasis Ijuk
}

Wulan K. Wardani ${ }^{*}$, Mariana B. Malino ${ }^{a}$, Asifa Asria

aProdi Fisika, Fakultas MIPA, Universitas Tanjungpura,

Jalan Prof. Dr. Hadari Nawawi, Pontianak, Indonesia

*Email : wulan.fisika2013@gmail.com

\begin{abstract}
Abstrak
Penelitian untuk fabrikasi dan analisis kualitas papan komposit semen berbobot ringan berbasis ijuk telah dilakukan. Penelitian ini bertujuan untuk fabrikasi papan komposit semen berbobot ringan dan analisis komposisi ijuk dan semen yang optimum ditinjau dari bobot, densitas, daya serap air (DSA) dan sifat mekanis. Komposisi papan komposit yang difabrikasi terdiri atas semen sebagai filler, ijuk sebagai matriks, aditif $\mathrm{CaCl}_{2}$ sebagai katalis dan air. Papan komposit dibuat dalam 6 variasi dengan perbandingan fraksi massa antara ijuk dan semen, yaitu 1:1, 1,5:1, 2:1, 2,5:1, 3:1, 3,5:1. Aditif $\mathrm{CaCl}_{2}$ yang digunakan sebanyak $15 \%$ dari massa total semen. Hasil dan metode pengujian papan komposit mengacu pada standar ASTM C 1185. Nilai optimum diperoleh pada papan komposit semen komposisi 1,5:1 dengan densitas sebesar $1,89 \pm 0,01 \mathrm{~g} / \mathrm{cm}^{3}$, DSA sebesar $8,90 \pm 0,16 \%$, modulus of rupture (MOR) sebesar 10,03 $\pm 1,83 \mathrm{MPa}$ dan modulus of elasticity (MOE) sebesar 3,20 $1,53 \mathrm{GPa}$. Semakin tinggi densitas semakin rendah DSA papan komposit semen. Bobot papan komposit semen berbasis ijuk yang optimum lebih ringan $20 \%$ dari papan komposit semen komersil. Nilai densitas, DSA, dan MOR semuanya memenuhi standar ASTM C 1186.
\end{abstract}

Kata Kunci : Papan semen, komposit, ijuk, $\mathrm{CaCl}_{2}$, densitas, DSA, MOR dan MOE

\section{Latar Belakang}

Kebutuhan papan serta pemakaian material yang aman, ramah lingkungan, dan bisa didaur ulang (renewable) merupakan tuntutan yang harus dipenuhi dalam pembangunan bangunan[1]. Material yang mampu memenuhi tuntutan tersebut adalah kayu. Namun produksi kayu di Indonesia hanya sebesar 25 juta $\mathrm{m}^{3}$ pertahun sedangkan kebutuhan kayu diperkirakan mencapai 75 juta $\mathrm{m}^{3}$ pertahun[2]. Keadaan tersebut membuat perlu ada material baru untuk menggantikan fungsi kayu. Material yang diharapkan mampu untuk menyelesaikan masalah tersebut adalah material komposit. Salah satu produk material komposit yang cukup menjanjikan adalah papan komposit. Contoh jenis papan komposit yaitu papan partikel dan papan komposit semen[3].

Papan semen komersil (Glassfibre Reinforced Cement, GRC) yang digunakan sebagai plafon memiliki bobot yang tinggi. Penyebab bobot yang tinggi pada papan komposit semen komersil adalah akibat komponen penyusun semen yang bertindak sebagai matriks. Oleh karena itu perlu dilakukan penelitian mengenai papan komposit untuk mereduksi bobot papan semen yakni dengan cara mengatur komposisi komponen penyusun komposit dengan semen difungsikan sebagai filler[4].

Indonesia merupakan salah satu negara penghasil serat ijuk di dunia dengan kapasitas 164,39 kilo ton/tahunnya[5]. Ijuk memiliki densitas sebesar $1,14 \mathrm{~g} / \mathrm{cm}^{3}$ dan kekuatan tarik sebesar 208,22 MPa. Ijuk memiliki nilai MOE sebesar 5,37 GPa[6]. Salah satu syarat suatu material bisa dijadikan matriks adalah memiliki nilai MOE yang lebih rendah dibandingkan dari material yang dijadikan filler[7]. Ketersedian ijuk melimpah di alam dan tingkat keelastisan tinggi, ringan, tidak mudah rusak oleh perubahan cuaca dan sulit dicerna oleh organisme perusak. Berdasarkan kelebihan sifat tersebut, maka material serat alam yang akan dijadikan sebagai matriks adalah ijuk yang sekaligus menjadi keterbaruan pada penelitian di bidang papan komposit semen[5].

Peningkatan kerapatan dan kekuatan mekanis serta penurunan daya serap air papan komposit semen dapat dilakukan dengan penambahan aditif yang tepat[8]. Pada penelitian Sotande dkk.[9] papan komposit semen dengan nilai MOR tertinggi menggunakan aditif $\mathrm{CaCl}_{2}$ yaitu sebesar 13,57 MPa, sedangkan menggunakan aditif $\mathrm{AlCl}_{3}$ nilai MOR sebesar $11,02 \mathrm{MPa}$ dan menggunakan aditif $\mathrm{MgCl}_{2}$ sebesar 12,79 MPa. Menurut Abadi[8] ada faktor kesesuaian antara unsur-unsur kalsium yang terkandung dalam semen dan aditif $\mathrm{CaCl}_{2}$.

Oleh karena itu, penelitian ini bertujuan untuk fabrikasi dan analisis komposisi ijuk dan semen yang optimum ditinjau dari bobot, densitas, daya serap air (DSA) dan sifat mekanis. Fabrikasi dan analisis komposisi yang sesuai antara ijuk dan semen terhadap kualitas papan komposit yang dihasilkan guna menghasilkan papan komposit semen berbobot ringan. 


\section{Metodologi}

\subsection{Alat dan bahan}

Alat-alat yang digunakan adalah oven pemanas, alat kempa hidrolik (cold press), Universal Testing Mechine (UTM), moisture meter, jangka sorong, mikrometer sekrup, batch adukan, sircular saw, sekop semen, cetakan, plat besi, plastik packing, allumunium foil, mistar, dan timbangan digital. Bahan yang digunakan adalah ijuk, semen portland, $\mathrm{NaOH}, \mathrm{CaCl}_{2}$, dan air.

\subsection{Persiapan bahan baku}

Ijuk dicuci, dipotong menjadi $2 \mathrm{~cm}$ dan direndam dengan $\mathrm{NaOH}$ selama 2 jam kemudian dicuci hingga netral. Selanjutnya dioven pada suhu $85^{\circ} \mathrm{C}$ dalam waktu 24 jam dengan target kadar air mencapai $\pm 5 \%$.

\subsection{Pembuatan papan semen dengan komposisi $100 \%$ semen}

Bahan baku utama yaitu semen dan air dicampur hingga menjadi pasta semen. Air yang digunakan sebanyak $20 \%$ dari massa total semen. Pasta semen dimasukkan ke dalam cetakan dengan dimensi panjang $\times$ lebar $\times$ tinggi adalah $30 \times 30 \times 5 \mathrm{~cm}$ kemudian ditekan dengan kekuatan $420 \mathrm{kN}$ selama $2 \times 10$ menit. Papan semen dijemur selama 1 minggu. Tahap terakhir pengujian densitas, daya serap air dan mekanis.

\subsection{Pembuatan papan komposit semen}

Bahan utama ijuk, semen, air dan $\mathrm{CaCl}_{2}$ ditimbang dengan perbandingan fraksi massa ditunjukkan pada Tabel 1. Semua bahan dicampur hingga homogen kemudian dimasukkan ke dalam cetakan dengan ukuran $(30 \times 30 \times 5) \mathrm{cm}$ lalu ditekan dengan kekuatan $420 \mathrm{kN}$ selama $2 \times 10$ menit. Papan semen dikondisikan selama 1 hari pada suhu ruang, kemudian dijemur selama \pm 6 hari hingga komposit memiliki kandungan kelembaban maksimal sebesar 10-15\%. Selanjutnya papan komposit dipotong sesuai standar ASTM C 1185 untuk dilakukan pengujian densitas, DSA dan mekanis.

Tabel 1. Perbandingan fraksi massa

\begin{tabular}{ccccc}
\hline \multirow{2}{*}{ Variasi } & \multicolumn{4}{c}{ Perbandingan fraksi massa } \\
& Ijuk & Semen & Air & $\mathrm{CaCl}_{2}$ \\
\hline $\mathbf{1}$ & 1 & 1 & 0,2 & 0,15 \\
$\mathbf{2}$ & 1,5 & 1 & 0,2 & 0,15 \\
$\mathbf{3}$ & 2 & 1 & 0,2 & 0,15 \\
$\mathbf{4}$ & 2,5 & 1 & 0,2 & 0,15 \\
$\mathbf{5}$ & 3 & 1 & 0,2 & 0,15 \\
$\mathbf{6}$ & 3,5 & 1 & 0,2 & 0,15 \\
\hline
\end{tabular}

\subsection{Pengujian papan komposit semen}

Sebagai indikator keberhasilan fabrikasi papan komposit semen maka dilakukan pengujian densitas, DSA, dan mekanis yang mengacu pada standar ASTM C 1185 dan ASTM C 1186. Kerapatan dihitung berdasarkan persamaan ASTM C 1185.

$$
K=\frac{a \cdot W}{W-V}
$$

$\mathrm{K}$ adalah densitas komposit $\left(\mathrm{g} / \mathrm{cm}^{3}\right)$, $a$ adalah densitas air $\left(\mathrm{g} / \mathrm{cm}^{3}\right)$, W adalah massa komposit di udara (g).

DSA dihitung berdasarkan persamaan ASTM C 1185.

$$
\mathrm{DSA}=\frac{m_{1-} m_{2}}{m_{2}} \times 100 \%
$$

DSA adalah daya serap air (\%), $m_{1}$ adalah massa setelah direndam $(\mathrm{g})$, dan $m_{2}$ adalah massa sebelum direndam (g).

Sifat mekanis dihitung berdasarkan persamaan ASTM C 1185, dan Mallick[10].

$$
\begin{aligned}
& M O E=\frac{F_{m a k s} \cdot l^{3} \cdot g}{4 b \cdot h^{3} \delta} \\
& M O E=\frac{3}{8} E_{L}+\frac{5}{8} E_{T} \\
& M O R=\frac{3 F_{m a k s} . l . g}{2 b \cdot h^{2}}
\end{aligned}
$$

MOE adalah modulus elastisitas $\left(\mathrm{N} / \mathrm{m}^{2}\right), M O R$ adalah Modulus patah $\left(\mathrm{N} / \mathrm{m}^{2}\right), E_{L}$ adalah MOE longitudinal $\left(\mathrm{N} / \mathrm{m}^{2}\right), \quad E_{T}$ adalah MOE transversal $\left(\mathrm{N} / \mathrm{m}^{2}\right), F_{\text {maks }}$ adalah beban sampai batas proporsi $(\mathrm{kg}), l$ adalah panjang bentangan contoh uji (m), $\delta$ adalah defleksi setiap perubahan beban (m), $b$ adalah lebar contoh uji (m), $h$ adalah tebal contoh uji (m), dan $g$ adalah percepatan gravitasi bumi $\left(\mathrm{m} / \mathrm{s}^{2}\right)$.

\section{Hasil dan Pembahasan}

\subsection{Hasil fabrikasi papan semen dengan komposisi $100 \%$ semen}

Fabrikasi papan semen bertujuan untuk mengetahui nilai parameter mekanis semen (MOE dan MOR). Hasil parameter mekanis papan semen dijadikan acuan untuk membuat papan komposit semen.

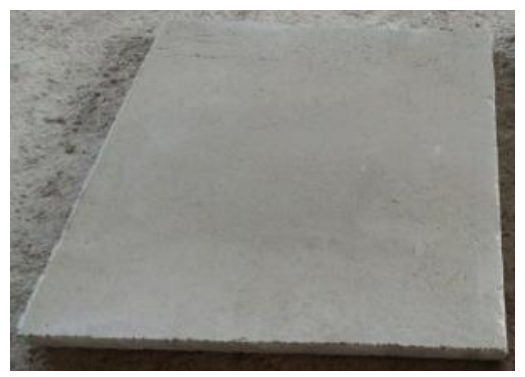

Gambar 1. Papan semen 
Gambar 1 menunjukkan papan semen dengan komposisi 100\% semen. Permukaan papan semen yang telah difabrikasi menunjukkan pori-pori yang tidak seragam pada bagian tepi. Ketidakseragaman pada permukaan papan semen terjadi pada saat penjemuran. Temperatur lingkungan saat penjemuran fluktuatif dalam kisaran 22,2-34,6 ${ }^{\circ} \mathrm{C}$ sehingga pengeringan papan semen tidak merata. Bagian tepi papan semen diduga memiliki kadar air lebih rendah dibandingkan bagian tengah. Hal tersebut mengakibatkan bagian tepi papan semen berpori lebih besar daripada bagian tengah dan cenderung berpotensi retak.

\subsection{Hasil fabrikasi papan komposit semen berbasis ijuk}

Gambar 2 menunjukkan hasil fabrikasi papan komposit semen berbasis ijuk dari 6 variasi komposisi. Permukaan papan komposit semen untuk komposisi dengan perbandingan 1:1 dan 1,5:1 masih tertutup oleh semen, sementara pada keempat komposisi yang lain serat-serat ijuk tampak jelas dipermukaan papan komposit. Sejumlah serat yang muncul pada permukaan dan bagian tepi untuk keempat komposisi yang lain tersebut juga ada yang terlepas karena tidak terikat kuat.

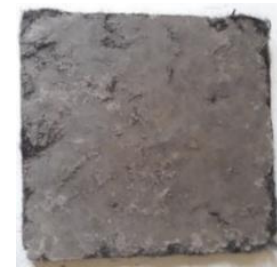

(1)

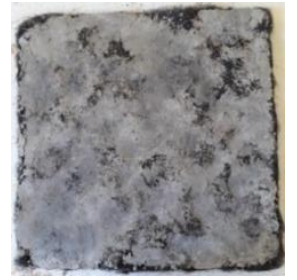

(3)

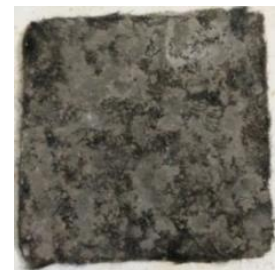

(5)

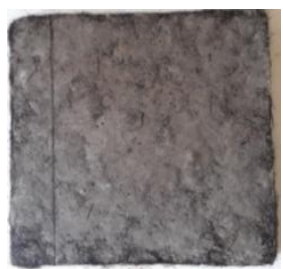

(2)

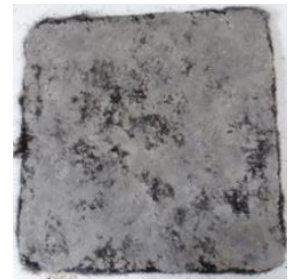

(4)

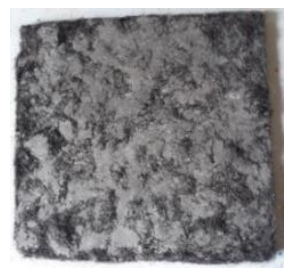

(6)
Gambar 2. Papan komposit semen dengan komposisi ijuk:semen (1) $1: 1$; (2) 1,5:1, (3) 2:1, (4) 2,5:1, (5) 3:1, dan (6) $3,5: 1$

\subsection{Hasil pengujian papan semen dengan komposisi $100 \%$ semen}

Pembuatan dan pengujian papan semen dengan komposisi 100\% semen bertujuan untuk mengetahui properti mekanis dari papan semen yaitu nilai MOE dan MOR. Nilai MOE dan MOR papan semen diperoleh dari hasil uji tekuk. Uji tekuk dilakukan dengan memberi tekanan tegak lurus terhadap papan semen.

Nilai MOR diperoleh dengan menggunakan persamaan (5) dan MOE diperoleh dengan menggunakan persamaan (3). Nilai MOR dan MOE papan semen merupakan nilai MOR dan MOE tiga papan semen yang dirata-ratakan. Berdasarkan uji tekuk yang dilakukan diperoleh nilai MOR papan semen sebesar $45,10 \pm 1,83 \mathrm{MPa}$

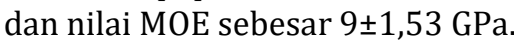

Syarat sebuah material menjadi matriks ialah memiliki nilai MOE lebih rendah dari filler[7]. Nilai MOE ijuk sebesar 5,37 GPa[6]. Maka dari itu semen dapat digunakan sebagai filler pada papan komposit semen berbasis ijuk.

\subsection{Hasil Pengujian dan Analisis Pengaruh Komposisi Ijuk dan Semen}

3.4.1 Densitas papan komposit semen berbasis ijuk

Nilai densitas papan komposit diperoleh dengan menggunakan persamaan (1). Nilai densitas papan komposit merupakan nilai densitas dari tiga papan komposit yang dirataratakan pada tiap variasi. Gambar 3 merupakan grafik pengaruh komposisi ijuk terhadap nilai densitas. Gambar 3 menunjukkan nilai densitas papan komposit adalah antara 1,73-1,98 g/ $\mathrm{cm}^{3}$. Densitas tertinggi dimiliki oleh papan komposit dengan perbandingan fraksi massa ijuk dan semen 1:1 dan terendah pada papan komposit semen dengan perbandingan fraksi massa ijuk dan semen 3,5:1. Berdasarkan standar ASTM C 1186, papan semen komposit berbasis ijuk telah memenuhi standar densitas minimal $\geq 1,59$ $\mathrm{g} / \mathrm{cm}^{3}$. Nilai densitas papan komposit semen berbasis ijuk lebih tinggi daripada papan komposit semen berbasis kertas/sekam padi yaitu $1,63 \mathrm{~g} / \mathrm{cm}^{3}[11]$.

Hasil uji densitas pada Gambar 3 menunjukkan bahwa semakin tinggi komposisi ijuk dalam papan komposit semen maka semakin rendah nilai dari densitas papan komposit semen. Penurunan nilai densitas pada papan komposit semen diakibatkan oleh peningkatan komposisi ijuk. Ijuk memiliki densitas 1,14 $\mathrm{g} / \mathrm{cm}^{3}$ [5], dan berdasarkan komponen penyusun semen menunjukkan bahwa densitas komponenkomponen penyusun semen berkisar 1,92-6,31 $\mathrm{g} / \mathrm{cm}^{3}$. Densitas semen untuk produk yang sama dengan yang dipakai dalam penelitian adalah $3,35 \mathrm{~g} / \mathrm{cm}^{3}$. Jadi penurunan densitas seiring 
dengan peningkatan jumlah ijuk bersumber dari sifat fisis bawaan komponen ijuk dan semen.

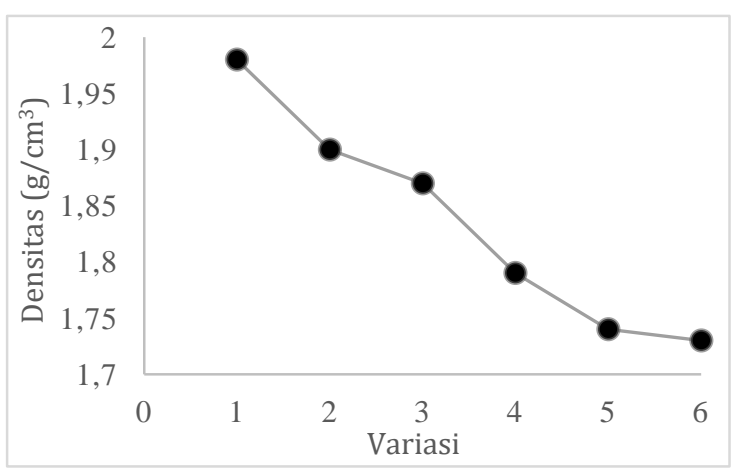

Gambar 3. Grafik nilai densitas papan komposit pada tiap variasi

Sebagai pembanding telah dilakukan pengukuran densitas pada papan komposit semen komersil dengan nilai densitas sebesar $1,94 \mathrm{~g} / \mathrm{cm}^{3}$ dan massa sebesar $115 \mathrm{~g}$. Pada segi massa, papan komposit semen komersil lebih tinggi 20\% dari papan komposit semen berbasis ijuk. Peran semen pada papan komposit semen komersil sebagai matriks dan densitas semen yang tinggi menyebabkan bobot papan komposit semen komersil menjadi tinggi. Dengan demikian sasaran penelitian yang dilakukan yakni menghasilkan papan komposit semen berbobot ringan telah terpenuhi.

\subsubsection{DSA papan komposit semen berbasis ijuk}

Nilai DSA papan komposit diperoleh dengan menggunakan persamaan (2). Nilai DSA papan komposit merupakan nilai DSA dari tiga papan komposit yang dirata-ratakan pada tiap variasi. Pada Gambar 4, nilai DSA papan komposit setelah direndam selama 48 jam memiliki nilai antara 7,34\% - 23,22\%. DSA terendah papan komposit adalah pada variasi 1 yaitu 7,38 $\pm 0,16 \%$ dan yang tertinggi adalah pada variasi 6 yaitu $23,22 \pm 0,40 \%$.

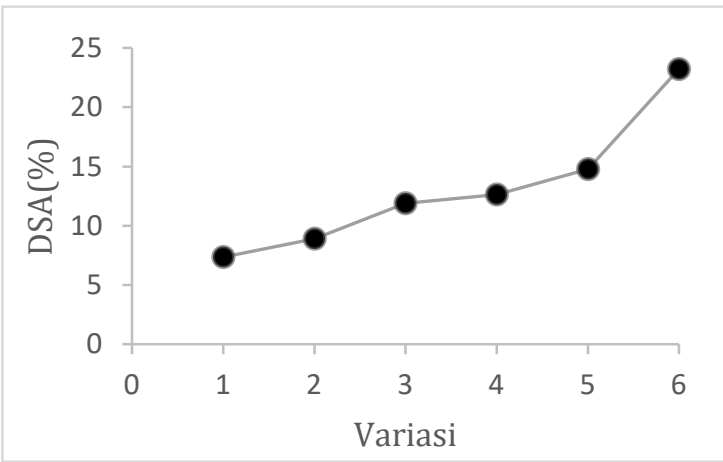

Gambar 4. Grafik nilai daya serap air (DSA) pada tiap variasi
Standar ASTM C 1186 mensyaratkan bahwa papan komposit semen harus memiliki daya serap air maksimal 15\%. Sehingga hanya papan komposit semen berbasis ijuk dengan komposisi perbandingan antara ijuk dan semen 3,5:1 yang tidak memenuhi standar ASTM C 1186. Nilai DSA papan komposit semen berbasis ijuk lebih rendah daripada papan komposit semen berbasis kertas/sekam padi yaitu 30,01\% (tidak memenuhi standar ASTM C 1186)[11]. Gambar 4 menunjukkan bahwa semakin besar komposisi ijuk maka semakin besar pula daya serap air papan komposit. DSA papan komposit berbanding terbalik dengan densitas komposit. Celah yang muncul seiring pertambahan komposisi ijuk menjadi salah satu penyebab DSA papan komposit semen mengalami peningkatan. Celah terjadi akibat struktur komponen ijuk yaitu middle lamella yang sukar berikatan dengan semen. Middle lamella terdiri dari lignin dan pectin. Sifat middle lamella yang kohesif[12] membuat ijuk sukar berikatan dengan semen sehingga perlu dihilangkan menggunakan perlakuan $\mathrm{NaOH}$.

Sebagai pembanding, telah dilakukan pengujian DSA papan komposit semen komersil dan papan komposit semen berbasis ijuk tanpa perlakuan $\mathrm{NaOH}$. Nilai DSA papan komposit semen komersil berkisar 12\%. Nilai tersebut lebih tinggi dari DSA papan komposit semen berbasis ijuk pada variasi 1, 2, dan 3. Hasil pengujian DSA terhadap papan komposit semen berbasis ijuk tanpa perlakuan $\mathrm{NaOH}$ adalah $13 \%$. Hasil tersebut menunjukkan bahwa penggunaan perlakuan $5 \% \quad \mathrm{NaOH}$ berhasil mengikis permukaan ijuk (middle lamella).

\subsubsection{Elastisitas papan komposit semen berbasis ijuk}

Dilakukan pengujian untuk memperoleh elastisitas papan komposit yaitu uji tekuk. Berdasarkan hasil uji tekuk yang telah dilakukan diperoleh nilai MOE seperti terlihat pada Gambar 5. Nilai MOE dari hasil percobaan diperoleh menggunakan persamaan (3).

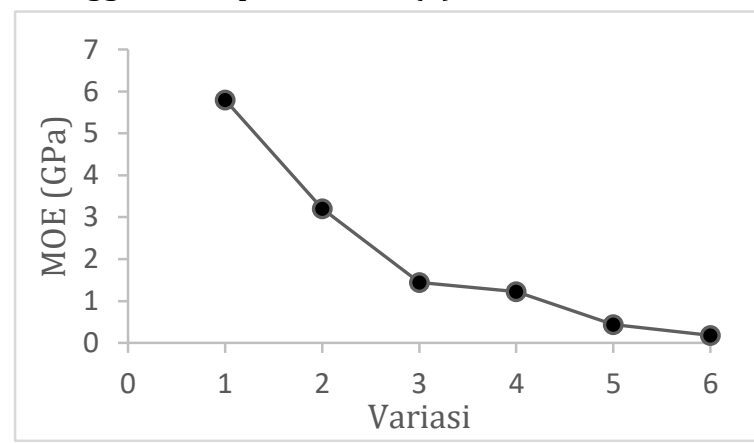

Gambar 5. Grafik nilai MOE pada tiap variasi 
Standar ASTM tidak mensyaratkan nilai MOE. Pada Gambar 5, nilai MOE papan komposit berkisar antara 0,18 GPa - 5,80 GPa. Nilai MOE tertinggi terdapat pada variasi 1 yaitu 5,80 $\pm 3,76$ $\mathrm{GPa}$ dan nilai MOE terendah terdapat pada variasi 6 yaitu $0,18 \pm 0,08 \mathrm{GPa}$. Nilai MOE pada Gambar 5 menunjukkan hubungan yang linier antara komposisi ijuk terhadap nilai MOE. Semakin meningkat komposisi ijuk di dalam papan komposit semen maka nilai MOE semakin rendah.

Ijuk dan semen memiliki nilai MOE masingmasing yaitu 5,37 $\mathrm{GPa}$ [6] dan $9 \mathrm{GPa}$. Nilai MOE pada komposit berada diantara nilai MOE yang dimiliki oleh komponen penyusun komposit. Berdasarkan nilai MOE material penyusun papan komposit, nilai MOE papan komposit dapat dihitung dengan mengunakan persamaan (4). Persamaan tersebut menunjukkan kisaran nilai MOE yang bisa dimiliki oleh komposit berdasarkan material penyusun komposit. Berikut ini Tabel 2 perbandingan nilai MOE berdasarkan pengujian mekanis dan berdasarkan material penyusun.

Tabel 2. Perbandingan nilai MOE berdasarkan pengujian mekanis dan berdasarkan material penyusun

\begin{tabular}{ccc}
\hline Variasi & $\begin{array}{c}\text { MOE dari hasil } \\
\text { pengujian } \\
\text { mekanis (GPa) }\end{array}$ & $\begin{array}{c}\text { MOE teoritis } \\
\text { berdasarkan } \\
\text { pers 4. (GPa) }\end{array}$ \\
\hline $\mathbf{1}$ & $5,80 \pm 3,76$ & 7,70 \\
$\mathbf{2}$ & $3,20 \pm 1,53$ & 7,46 \\
$\mathbf{3}$ & $1,44 \pm 0,30$ & 7,31 \\
$\mathbf{4}$ & $1,22 \pm 0,85$ & 7,20 \\
$\mathbf{5}$ & $0,44 \pm 0,08$ & 7,12 \\
$\mathbf{6}$ & $0,18 \pm 0,08$ & 7,05 \\
\hline
\end{tabular}

Berdasarkan Tabel 2, nilai MOE papan komposit semen berbasis ijuk hasil penelitian berbeda dari nilai MOE hasil perhitungan berdasarkan material penyusun komposit. Nilai MOE papan komposit hasil penelitian yang rendah diduga karena ikatan antara materialmaterial penyusun komposit yang lemah.

Papan komposit semen berbasis ijuk terdiri dari semen, air, $\mathrm{CaCl}_{2}$ dan ijuk. Air berfungsi sebagai perekat butiran-butiran semen sehingga membentuk pasta semen. Semen terdiri dari oksida logam diantaranya kalsium oksida (CaO)[13]. Reaksi kimia yang terjadi pada semen (CaO) dan air:

$$
\mathrm{CaO}_{(\mathrm{s})}+\mathrm{H}_{2} \mathrm{O}_{(\mathrm{l})} \rightarrow \mathrm{Ca}(\mathrm{OH})_{2}(\mathrm{l})
$$

$\mathrm{CaO}$ (Kapur) berinteraksi dengan air menghasilkan kalsium hidroksida $\left(\mathrm{Ca}(\mathrm{OH})_{2}\right)$. Berdasarkan teori asam basa lewis kalsium hidroksida tergolong dalam senyawa basa kuat[14]. Pemercepatan proses hidrasi (pengerasan) melalui penambahan $\mathrm{CaCl}_{2}$ dapat ditelusuri melalui reaksi:

$$
\mathrm{CaCl}_{2(\mathrm{~s})}+\mathrm{H}_{2} \mathrm{O}_{(\mathrm{l})} \rightarrow \mathrm{Ca}^{+}+\mathrm{Cl}^{-}
$$

Kalsium klorida $\left(\mathrm{CaCl}_{2}\right)$ di dalam air mengion menjadi $\mathrm{Ca}^{+}$dan $\mathrm{Cl}^{-}$karena merupakan garam elektrolit kuat. Menurut Khisar dkk.[15], pemercepatan proses hidrasi terjadi akibat kenaikan $\mathrm{pH}$ pada pasta semen (bersifat basa kuat). Hasil hidrolisis $\mathrm{CaCl}_{2}$ yaitu ion $\mathrm{Ca}^{2+}$ meningkatkan derajat kelarutan $\mathrm{Ca}(\mathrm{OH})_{2}$ sedangkan $\mathrm{Cl}^{-}$dapat meningkatkan suhu larutan meningkat karena sifat dari $\mathrm{Cl}^{-}$mudah menguap (volatile). Kenaikan derajat kelarutan $\mathrm{Ca}(\mathrm{OH})_{2}$ menunjukkan bahwa terjadi kenaikan nilai $\mathrm{pH}$ pada pasta semen dan terjadi ikatan yang kuat antara semen dan $\mathrm{CaCl}_{2}$.

\subsubsection{Keteguhan patah}

Telah dilakukan uji tekuk pada enam variasi komposisi papan komposit. Berikut ini adalah grafik (Gambar 6) nilai MOR papan komposit pada tiap variasi. Nilai yang ditampilkan adalah nilai rata-rata dari enam variasi komposisi antara ijuk dan semen. Nilai MOR papan komposit diperoleh menggunakan persamaan 5 .

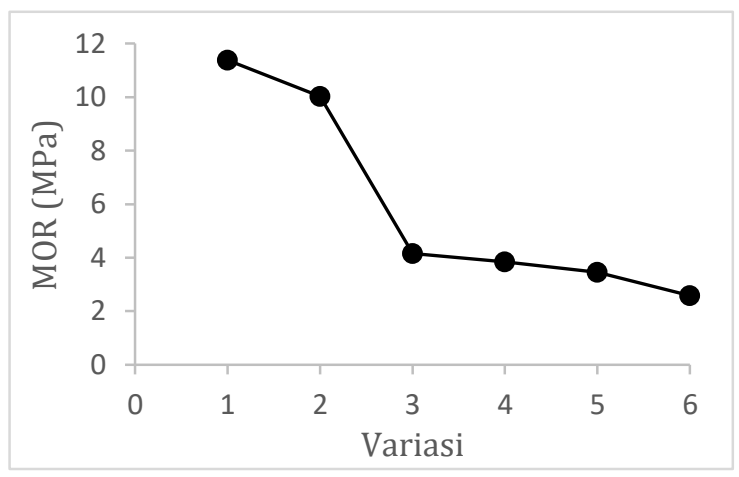

Gambar 6. grafik nilai MOR

Berdasarkan hasil uji tekuk diperoleh nilai MOR sebesar 11,39-2,58 MPa. Standar ASTM C 1186 mensyaratkan bahwa nilai MOR yang dimiliki oleh papan komposit semen lebih dari 9,99 MPa. Pada Gambar 6, nilai MOR tertinggi terdapat pada variasi 1 yaitu $11,39 \pm 3,12 \mathrm{MPa}$ dan nilai MOR terendah terdapat pada variasi 6 yaitu 2,58 $\pm 0,27 \mathrm{MPa}$. Nilai MOR papan komposit semen berbasis ijuk lebih tinggi daripada papan komposit semen berbasis kertas/sekam padi yaitu 6,99 $\mathrm{MPa}[11]$.

Gambar 6 menunjukkan pengaruh komposisi ijuk pada keteguhan patah papan komposit semen berbasis ijuk. Semakin tinggi komposisi ijuk maka semakin rendah nilai MOR papan komposit semen. Penurunan nilai MOR diakibatkan oleh gaya rekat antara semen dengan ijuk semakin menurun. Penurunan gaya rekat ijuk dan semen diakibatkan oleh jumlah 
ijuk semakin meningkat. Berdasarkan Gambar 2 hasil fabrikasi papan komposit tiap variasi, semakin tinggi komposisi ijuk maka semen semakin sulit mengikat ijuk karena jumlah ijuk yang semakin banyak. Variasi komposisi yang memenuhi standar ASTM C 1186 untuk nilai MOR papan komposit semen hanya variasi 1 dan 2 dengan nilai $11,39 \pm 3,12 \mathrm{MPa}$ dan $10,03 \pm 0,27$ MPa. Pada variasi 3, 4, 5 dan 6 tidak memenuhi standar ASTM C 1186. Hal ini diduga karena komposisi ijuk yang jauh lebih besar daripada semen, sehingga ikatan antara ijuk dan semen lemah dan mengakibatkan nilai mekanis papan komposit rendah.

\section{Kesimpulan}

Berdasarkan penelitian yang telah dilakukan dapat disimpulkan bahwa komposisi yang sesuai antara ijuk dan semen adalah pada variasi 2 ditinjau dari, nilai densitas papan sebesar 1,89 $\pm 0,01 \mathrm{~g} / \mathrm{cm}^{3}$ dan memiliki bobot lebih rendah $20 \%$ dari papan komposit semen

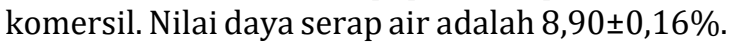
Nilai MOE papan komposit semen variasi 2 adalah 3,2 $\pm 1,53 \mathrm{GPa}$. Nilai MOR papan komposit semen variasi 2 adalah 10,03 $\pm 1,83 \mathrm{MPa}$. Nilai densitas, DSA dan MOR memenuhi standar ASTM C 1186.

\section{Daftar Pustaka}

[1] Idawati, Setyawati, D., Nurhaida and Diba, F., Kualitas Papan Komposit Batang Kelapa Sawit (Elaeis Guineensis Jacq) dan Limbah Plastik Polipropilena Berbagai Variasi Rasio dan Penambahan Maleic Anhydrid, Jurnal Hutan Lestari, 2(3), 546-554, 2014.

[2] Olanda, S. and Mahyudin, A., Pengaruh Penambahan Serat Pinang (Areca Catechu L Fiber) Terhadap Sifat Mekanik dan Sifat Fisis Bahan Campuran Semen Gymsum. Jurnal Fisika Unand, 2(2), 2013.

[3] Saputra, A. S., Pengajian Sifat Fisik dan Mekanik Papan Semen Partikel Pelepah Aren (Arenga Pinnata), Fakultas Teknik Universitas Negeri Semarang, 2014.

[4] Qorina, U., Mahyudin, A. and Handani, S., Pengaruh Persentase Massa Gipsum dan Serat terhadap Kuat Tekan dan Kuat Lentur Papan Semen - Gipsum Berserat Eceng Gondok, Jurnal Fisika Unand, 5(3), 233-237, 2016.

[5] Christiani, E., Karakterisasi Ijuk Pada Papan Komposit Ijuk Serat Pendek Sebagai Perisai Radiasi Neutron, Sekolah Pasca Sarjana Universitas Sumatera Utara, 2008.

[6] Munandar, I. and Savetlan, S. S., Kekuatan Tarik Serat Ijuk, Jurnal FEMA, 1, 3, 2013.
[7] Callister, W. D., Materials Science and Engineering, Fifth ed., United States of America, 2007.

[8] Abadi, M., Pengaruh Variasi Penambahan Aditif $\mathrm{CaCl}_{2}$ Terhadap Karakteristik Fisik dan Kekuatan Lentur Komposit Semen Serbuk Aren (Arenga Pinata), Universitas Sebelas Maret, 2010.

[9] Sotande, O. A., Oluwadare, A. O., Ogedoh, O. and Adeogun, P. F., Evaluation of CementBonded Particle Board Produced from Afzelia Africana Wood Residus, Journal of Engineering Science and Technology, 7, 2012.

[10] Mallick, P. K., Fiber-Reinforced Composites, Departement of Mechanical Engineering University of MichiganDearborn, 2008.

[11] Shawia, N. B., Jabber, M. A. and Mamouri, A. F., Mechanical and Physical Properties of Natural Fiber Cement Board for Building Partitions, Physical Sciences Research International, 2(3), 49-53, 2013.

[12] Arini, N. A., Analisis Pengaruh Waktu Hidrolisis terhadap Sifat Mekanis Selulosa Kristalin dari Campuran Serbuk Kayu Belian, Bengkirai, Jati, dan Meranti, Universitas Tanjungpura, 2015.

[13] Elita, B., Penggunaan Lumpur Hasil Pengolahan Perusahaan Daerah Air Minum (PDAM) Sebagai Bahan Campuran Pembuatan Bata Beton, Universitas Tanjungpura, 2012.

[14] Huheey, J. E., Keiter, E. A. and Keiter, R. L., Inorganic Chemistry: principles of Structure and Reactivity, Haper Collins College Publisher, 1993.

[15] Kishar, E. A., Ahmeed, D. A., Mohammed, M. R. and Noury, R., Effect of Calcium Chloride on Hydration Characteristics of Ground Clay Bricks Cement Pastes, Elsevier, 2(1), 20-30, 2012. 